\section{THE UNIVERSAL MERIDIAN}

II.

' $\mathrm{I}$, now, we examine the question of changes to be introduced into existing charts, these would, in accordance with our proposal, be imposed on the whole world; they might be greatly reduced, especially if people restricted themselves to what would be sufficient for a beginning, that is, by tracing on the existing plans only sufficient to allow us to make an immediate use of the international meridian. Later on, and in proportion as new plates were engraved, a more complete scale would be given; yet, in my opinion, it would always be of advantage to keep the two frameworks-the national and international-according to the example of what is done in several atlases.

"If, at the present time, it is necessary to facilitate external relations, it is also good for each people to maintain all the manifestations of its personal life and to respect the signs representing its traditions and its past.

"I do not insist on the details of the establishment of such a meridian. All we have to support before you is the principle of its acceptation.

"If this principle were admitted by the Congress, we are charged to inform you that you would there find a ground of agreement with France.

"Undoubtedly by reason of our long and glorious past, our great publications and our considerable hydrographic labours, a change of meridian would entail on us heavy and cruel sacrifices. Yet if one came to us, setting us an example of self-sacrifice, and thereby proving his sincere desire of the public weal, France has already given such proof of her love of progress that no doubt need be entertained of her concurrence in such an enterprise.

"But we should have to regret our inability to associate ourselves with a combination which, in order to safeguard the interests of one part of the contractors, sacrificed the higher scientific character of the institution, a character which in our opinion is indispensable if it would claim the right of imposing itself on all, and if it would secure to itself a definitive success."

Immediately after this discourse the general discussion was entered into, in which all the English and American delegates, and the Americans distinguished in science who had been invited, successively argued against the proposal of the French delegate. The latter had to reply successively to half a score of speeches embracing yarious phases of the question according to the various provinces of the speakers. It is, perhaps, allowable to say that notwithstanding the authority, talent and number of the distinguished speakers contending against the principle of the neutrality of the meridian, the principle withstood all those shocks without being shaken, and without suffering any scientific breach. The meridian proposed by France will remain always as representative of the impartial, scientific, and definitive solution of the question. We think it was a honour to our country to have defended this cause.

Before the vote, M. Cruls, the learned director of the Observatory of Rio de Janeiro, and delegate of Brazil, informed the French delegation that he had received instructions from the Emperor to vote with France. We were very glad at this concurrence of sentiment, and begged to be allowed to congratulate the august foreign associate of the Institute of France on his resolutions.

The following are the principal passages in the speech in which M. Cruls set forth the reasons of his vote :-

"Down to the present one point, and that of great importance, has been settled by the discussion-the necessity, namely, of fixing a single initial meridian. This point has, in fact, obtained the adhesion of all the delegates present at the Conference. This necessity recognised, it

${ }^{2}$ Lecture by Dr. Janssen at the Paris Geographical Society. Continued from p. I5I. is proper to take a step farther, and to determine which shall be this meridian. An election of this kind forms at this moment the object of our debates, and a question on which we should have to pronounce our opinion.

"Our honourable colleague, Mr. Rutherfurd, delegate of the United States, has made a motion proposing the adoption of the meridian of Greenwich-a motion for the moment eliminated from our debates, its author having decided to withdraw it temporarily.

"The motion which was made at the last sitting, and formed the subject of numerous and interesting debates, is that formulated by our honourable colleague, $M$. Janssen, delegate of France, proposing that the meridian to be adopted should have a neutral character, and should not touch either of the great continents of Europe and America. This proposal has been strongly combated by the delegates of England and the United States, and valiantly defended by the delegate of France, and the debates thus arising on the question have furnished us with the opportunity of witnessing a scientific tournament of the highest interest. The speakers we have had the honour of hearing seem to me to have exhausted the whole series of arguments for and against; and at this stage I presume that the debates have enabled us, in full knowledge of the case in dispute, to form each his own opinion on the question on which we are called to vote.

"For my part I am anxious to have clearly defined the attitude which in my opinion Brazil is called upon to take in the midst of this assembly. This attitude is one of absolute neutrality so far, be it understood, as it is a question of choosing a national meridian-a question which may provoke among certain nations very legitimate personal rivalries.

"Now, till the day when the Conference assembled for the first time, I was in hopes that these debates, entered into under the influence of a generous aspiration, and with the single object of arriving at the establishment of a measure, the necessity of which is warmly proclaimed by manifold interests of diverse nature, might conduct us to a complete and definitive solution of the question. Unhappily, and to my great regret, I am compelled to add that the differences which have manifested themselves in the midst of the assembly do not allow this hope to be maintained.

"That which for my part I am not able to lose from view is the fact that it is indispensable that the solution of the question for which the Conference is assembled should be complete; or the end of this Conference would not be attained. Now, since the delegates of France have from the beginning of our debates manifested their opposition to the adoption of any meridian invested with a national character, an opposition which gave rise to the motion presented by $M$. Janssen, it follows that any measure voted by the Conference and tending to the adoption of a national meridian would, by the very fact of the abstention of France, be an incomplete measure, not corresponding with the object pursued by the Conference. I hasten to add, for fear of any erroneous interpretation being given to my words, that the same objection would apply, if, for example, the meridian of Paris were proposed, and any great maritime nation, such as England, the United States, or any other abstained from its adoption. In such a case, likewise, my line of conduct would be fully indicated.

"In short, I will say that the immense benefits which would accrue to the whole world from the adoption of a single prime meridian would be forthcoming in all their plenitude only in so far as the measure was unanimously accepted by the most important maritime nations. In every other case I am for my own part absolutely convinced that the measure would be in part inefficacious, its adoption not being general, and that everything would have to be done over again in a more or less distant future. 
"Well, the debates at which we have assisted prove to me superabundantly that such will always be the unsatisfactory issue so long as the meridian of any great nation is proposed.

"In presence, then, of this difficulty, which on that supposition appears to me insuperable, the only solution which by its very nature will not excite burning questions of national jealousy is that of a meridian having a character of absolute neutrality. If the adoption of such a meridian were admitted in principle, I am certain that a discussion engaged in on the ground of pure science and directed according to the best conditions which such a ground is calculated to secure would soon lead to a practical solution.

"In such a discussion the arguments having any force should be, above all, drawn from science, the only source of truth alone able to enlighten us so as to guide us to a sound judgment and to a decision based solely on considerations of a purely scientific order.

"Such a practical solution seems to me, moreover, to be suggested by what our honourable colleague, M. Janssen, told us on this subject. The principle of the neutral meridian once adopted, the conditions it would require to fulfil and the determination of its site would remain to be discussed. Of two things-one, whether the meridian should be exclusively oceanic, and so by its very nature it would be neutral; or, second, whether it should cut some island, and in such a case there could be no obstacle, by means of an international diplomatic convention, in the way of rendering neutral the particle of ground on which it would be proper to establish an observatory, which in reality would be confined to a very small affairof these two solutions both of which would satisfy the conditions requisite for the meridian, from the double point of view of its character of neutrality and the demands of science, I prefer for my part the second. I confine myself to intimating by these few words how it would be possible to arrive at a practical solution, since at this moment I have to occupy myself simply with the adoption of the principle of the neutral meridian.

"I conclude, then, by declaring that 1 shall vote in favour of the adoption of a meridian invested with the character of absolute neutrality; and in doing so I hope thus to contribute my part to the end that our resolutions may bear the impress of independence which they require in order to impose themselves spontaneously and naturally, generalise themselves in the future and rally from the beginning the adhesion of men of science, without distinction of nationality, who at this hour await our decisions."

I have to add that before the vote M. Galvan, the very distinguished representative of the Dominican Republic, who had studied at Paris under our most eminent masters, very cordially informed me that the attitude of France in this matter appeared to him to conform with that which the world was in the habit of seeing it take in all questions of general interest, and that it would give him such happiness once more to contribute in bringing a testimony of admiration to the nation--to the puissante initiale de l'intellectuelle, to use his own expression-by voting with France.

As to the vote, it was according to our expectations, seeing that, as I have said, almost all the delegates had received instructions to vote for the meridian of Greenwich.

The principle of the neutral meridian being rejected, we abstained from taking part in the discussion in the choice of the national meridian called to become international. As we already said, we did not come to Washington to sustain a candidature, but a principle.

Before the vote, M. Valera, delegate of Spain, announced that he was charged by his Government to say that, in voting for Greenwich, Spain expressed the hope that England and the United States would accept the French system of weights and measures. This declaraticn led Gen. Strachey to say that he was authorised to announce to the Conference that England had asked to join the Metric Convention.

We cannot pass over in silence the part taken in this discussion by the eminent Foreign Associate of the Institute of France, Sir William Thomson, who was then in America, and had very naturally been invited to our sittings. Sir William Thomson expressed his desire of an accord in regard to the meridian and the metrical system. The following are among the few words he spoke on this subject :-

"I cherish the sincerest and most ardent desire that the delegates of France and those of the other nations who by this vote supported the previous resolution, will be able to adopt the resolution now before the Conference. It appears to me that we have here to do with a sacrifice, and I am convinced that the honourable delegate of France who last spoke, M. Lefaivre, will clearly apprehend that there is no question of asking a sacrifice of France which she is not disposed to make.

"In the admirable speech delivered by M. Janssen before this Conference (a speech I had not the pleasure and satisfaction of listening to, but which I read with the greatest interest) he declared that France was willing to make a much greater sacrifice than that now in question. The amount of sacrifice involved in changing certain usages is always more or less considerable, in view of the fact that it is impossible to say that such an innovation can be effected without derangement. It may, however, be asserted that the sacrifice France is prepared to make would be much more considerable than that ensuing from the adoption of the resolution now before us.

"If the resolution relative to a neutral meridian had been adopted, all nations would have been called on to make the sacrifice involved in a change of meridian not yet determined, and the relations of which to the meridiaus now in use could not have been so easy as would be those of the meridian of Greenwich with the meridians at present employed.

"I am of opinion that if the delegates of France could see their way to the adoption of this resolution, they would have no cause to regret it.

"I highly approve of what has been said in regard to a common metrical system. My opinion on this subject is firmly established, and I shall by no means express it if the President thinks it would be inexpedient to enter on this subject; but it seems to me that England makes a sacrifice in abstaining from adopting the metrical system. The question cannot, however, be presented under this form. We have not to consider here whether England would gain or lose by adopting the metrical system.

"Such is not the way of looking at the question, considering that the adoption of the metrical system by England is a question restricted to her own convenience, to her own usages, and that whether she adopted it or not, her decision could not in any way affect other nations. It could result neither in advantage nor disadvantage of other countries."

When the meridian of Greenwich was adopted, the Assembly considered that it devolved on it to define the principle according to which the longitudes should be numbered. Should they be counted in one single direction in accordance with the almost unanimous opinion of the distinguished members of the Conference of Rome, or should they continue to be counted in the two opposite directions, as far as the anti-meridian? The latter method was adopted.

The method of counting longitudes east and west, starting from a central meridian-the method actually in general use-was evidently introduced and actuated by the use of national meridians. But when, instead of looking merely at one country in particular, the entire earth is contemplated, and it is desired to bring the general system of longitude into relation with a universal 
time, it is difficult to understand how in counting the longitudes, one should stop in the middle of the way, while in counting the time one goes the whole round of the day, reckoning the hours from 0 to 24 , according to the decision of the Congress.

We are unwilling to believe that the advantage of not having to make any change in use and wont, not even to the extent of a few figures on English maps, was the ground of this decision on the part of the majority.

This majority, for the rest, consisted in a preponderance of but three votes, and among the opposite voters or abstentionists we observe all the great Powers, with the exception of Russia.

The question of a meridian being completely settled, the assembly had to address itself to the second part of its programme-that relating to universal time.

The commercial and maritime relations so developed at the present day by the prcgress of the marine and telegraphy render the inconveniences attending a diversity of origins in horary measures more sensible every day. It has, therefore, come to be desirable to establish a division of time having the same point of departure for the whole world. To attain this object the local time of a determined point is taken, and by a convention is made the universal time. In this system the influence of longitude is entirely eliminated. The same instant receives the same name all over the earth, and the acts of international life are dated in as close relation to each other in point of time as though they were acts transpiring all within the same town. As to the point to be chosen for giving the universal time, it is plain that it ought to be the same as that adopted for giving the departure of longitudes. The two systems cannot be separated.

As a matter of course, this universal time cannot claim to take the place of local time, nor of so-called national time. The local time, which is the expression for each place, at least very approximately, of the course of natural phenomena, the eternal regulators of the acts of life, can never be displaced. In the case of certain arrangements, such as that of railways, for example, is it found highly convenient to extend the use of the local time of the capital to the whole country, when this latter has not a too considerable range of longitude. Such is the case in France.

The Congress adopted in principle the establishment of a universal time defined in the manner I have just described. But, separating itself again on this point from the Congress of Rome, it assigned as the origin of the universal day the midnight of Greenwich, which, according to the proposals of the Washington Congress, should become the beginning of the day for international transactions all over the world.

The divergence of resolutions adopted at Rome and Washington in reference to the origin of the international day brings clearly into view the inconveniences of the vexatious disagreement still actually existing between the origin of the astronomical day placed at midday, and that of the civil day placed at the preceding midnight. This inconvenience grows greater and greater in proportion as the ephemerides and astronomical studies extend. We therefore eagerly associated ourselves to the resolution expressed by the Congress relative to the unification of the two systems, by making the astronomical day commence at midnight, like the civil day.

Astronomers will, we hope, understand that, being a far less numerous body, and much more conversant with these matters, it is on them that it devolves to make a slight sacrifice, so as to allow a progress very desirable at the present day to be effected.

After the discussion of these various questions, the labours of the Congress approached their term; it was then that the French delegation made the proposal it had been charged to present-a proposal having reference to an important extension of the decimal system.
The Congress of Washington, by its importance and by its object, which aimed definitively at the continuation of that great French work of unification and of progress inaugurated at the end of the last century, offered an altogether appropriate opportunity to ask for the world a new extension of those applications of the decimal system which constituted the whole merit and the whole success of our reform of weights and measures.

This extension had relation to the measurement of angles and of time.

At the date of the establishment of the metrical system the decimal division was, as is known, extended to the measure of angles and time. Numerous instruments were even constructed according to the new system. As far as time is concerned, the reform, introduced too drastically and without sufficient discretion, it may be said, clashed with too inveterate usages, and was rapidly abandoned; but in regard to the measure of angles, where the decimal division presents so many advantages, the reform held its ground much better, and has maintained itself in certain practices to this day. Thus, for example, the division of the circumference into 400 degrees was adopted from the beginning by Laplace, and it is currently employed in celestial mechanics. For the measurement of the arc of the meridian, whence the metre was derived, Delambre and Mechain availed themselves of repeating circles divided into $400^{\circ}$. Finally, in our days, Col. Perrier, Chief of the Geographical Service at our Ministry of War, makes use of instruments with decimal division, and at this moment calculates even logarithmic tables with eight decimals appropriated to this mode of division.

It is above all, however, when it is required to execute long calculations on angular measures that the decimal division presents immense advantages. On this point nothing but unanimity may now be said to reign among learned men.

The Conference of Rome, which assembled so many astronomers, geodesists, and eminent topographers-that is, just the men of most weight and having the greatest interest in the question-issued on this subject a resolution the high authority of which it is impossible to disregard.

It is now, then, evident that the decimal system, which has already rendered so many services in the measurements of length, of volumes, and of weights, is called upon to render analogous services in the domain of angular magnitudes and of time.

I am aware that this question of the decimal division has to contend with legitimate apprehensions, principally in reference to the measure of time. People are afraid of doing violence to secular customs and overturning consecrated usages. On this aspect of the business I think we ought to be fully assured. The lessons of the past will be put to profit. It will be understood how it was for having endeavoured to push a reform beyond the due domain of science, and for having done violence to the habits of daily life, that disaster was experienced during the epoch of the Revolution. It is proper to resume the question, but it is proper to resume it with an appreciation of the limits which good sense and experience will always indicate to wise and experienced men.

I think the character of the reform would be sufficiently indicated by saying that the question is principally to make a new effort towards the application of the decimal system in the scientific world.

We met at first with a sufficiently warm opposition. The President was of opinion that the proposal should not be offered for discussion, but I have to acknowledge that he finally yielded very courteously, "out of deference," he said, "to the delegates of France, and because we are happy to do them honour in all things."

The majority decided that the proposal should be discussed. The French delegate then spoke, and the meeting passed to the definitive vote. The success was 
then complete, for the proposal was adopted by twentyone votes, without one dissentient voice.

Such is the work of the Congress.

This work is considerable. Its importance, however, is derived much more from the principles enunciated by the Congress than from the solutions it adopted.

The establishment of a single meridian and of a universal day, the unification of the astronomical and civil days, the extension of the decimal system,--these are reforms which the progress of science and of international relations rendered opportune and desirable.

In the application, however, of the principles, the Congress has been less successful.

In the choice of a primary meridian it allowed itself to be too much carried away by the practical and immediate advantages of a meridian already in very extended use, and disregarded the conditions which would have assured to its work a universal and definitive adoption.

In regard to ourselves we have in this question adhered to the part prescribed to us by our past, our traditions, and the very character of our national genius. Our proposal was precisely that which we should have adopted ourselves if we had had to take the initiation of this reform. The nation which created the metrical system could propose none other than it did. If our purely scientific and disinterested opinion did not unite the majority around it, the reverse was not for France, but for science. But science is the sovereign of modern times and one cannot now detach himself from it with impunity. It is vain to say that the meridian of Greenwich is de facto the universal meridian, that it reigns to-day over almost all the navies of the globe, and that its adoption only consecrates a fact which has already established itself and transforms into law the institutions of fact.

I reply that that is all true. I even add, if it is desired, that such is only what is merited by the great labours of the English marine-labours which we, the initiators of hydrography, more than any others appreciate at their true value. But however considerable may be these labours and however great the numbers of those availing themselves of them, yet with the experience of the past and in the name of history I say that these merits will not be able to prevent the inevitable consequences resulting from the personal character of this meridian. And in point of fact, has not France-she, too-had a great geographical career? The meridian of the Island of Ferro, which soon, in the hands of Gillaume Delisle and of our great geographers of the eighteenth century, became French-did it not bear sway in cartography for more than two centuries, and that with an authority not even equalled to-day by that on the other side of the Channel?

And yet the meridian of the Isle of Ferro, after that brilliant career, is to-day more and more abandoned, and the fair attempt of the seventeenth century finds itself entirely compromised!

What is the cause, then, which has led to this vexatious result? Apparently a mere trifle. It is because, as we have already said, instead of leaving the meridian of the Isle of Ferro in conformity with its first intention, instead of maintaining it in the purely scientific character which it received from the hands of Richelieu, that great spirit who so well understood that an institution of a universal order must bear no personal investiture, this character was imprudently changed by bringing the position of this meridian into relation with that of Paris, in place of bringing the position of this capital, like any other point, into relation with it.

That is the mistake which compromised the fortune of this reform so firmly and so judiciously established by iis illustrious author. Now, this mistake, is it not committed to-day by once more taking a national meridian and making it the universal point of departure for longitudes? Is one not then justified in foreseeing that the same causes would produce the same effects, with this difference, nevertheless, that in the advanced state of civilisation prevailing to-day among the nations, a particular supremacy, of whatever nature, would be much more promptly abandoned than it was two centuries ago ?

It is, accordingly, much to be feared that the establishment of the new meridian, if it even succeed in getting established, would again be but an attempt without a future.

France who finds in the history even of her own past the double lesson of the progressive abandonment of her national meridian and of the ever growing appreciation of the scientific and impersonal system of weights and measures, ought to make known to the Congress a counsel dictated by her own experience.

Does this attitude, however, sufficiently absolve us? Have we discharged towards the world and towards ourselves the debt due by a generous and enlightened nation which has always been delighted to take the initiative in tasks conducive to the general well-being? I do not think so; and, were it allowed me to express a wish, it would be that we should on this occasion again join example to precept. I should like that the France of the nineteenth century, considering herself the heir of the France of the seventeenth, would, with the benefit of the experience she has in that interval acquired, resume the fair attempt of Richelieu and herself establish the neutral meridian.

This institution, well conceived and planted on exclusively scientific bases, would gradually rally to it the adhesion of all. England herself, who, if possessing a lively national sentiment, has likewise an appreciation of what is just and great, would end by attaching herself to it. and then would this reform so long desired, always attempted in vain, and again quite recently compromised, be finally secured to the world and to science.

Be that as it may, and outside the question of the meridian, which is not yet settled, let us not forget that the accession of England to the Metrical Convention and the resolution for the extension of the decimal syste $m$ are results demonstrating that our presence at Washing ton was not useless either to science or to progress.

\section{THE VOYAGE OF THE "CHALLENGER"1}

I.

NINE years have slipped away since the memorable expedition of the Challenger came to a close. During this interval from various published accounts of the voyage, the route around the world, the places called at, the life on board, the impressions, social or biological, left on the minds of the voyagers-are all now more or less familiar to us. There have likewise appeared numerous detailed quarto reports from different experts, into whose hands the great natural history collections amassed during the expedition were placed for description. We know precisely the additions made by the naturalists of the Challenger and their collaborateurs to our knowledge of the foraminifers, corals, medusæ, ostracods, brachiopods, echinoids, shore fishes, birds, and many other groups, and from the list of memoirs yet to come we can see how ample a store of detail is still to be produced. We know also how vast an amount of additional information has been gathered by the expedition regarding the physics and chemistry of the ocean. But as yet there has been no condensed official record of it all. The general public, and even the man of science, cannot be expected to master the series of special reports; life is too short for this, even if the power of comprehension were adequate. Admirable and exhaustive as the reports are, and indispensable for experts in the various branches of which they treat, each of these must necessarily appeal to a comparatively small

x "Report on the Scientific Resuits of the Voyage of H.M.S. Challenger during the years $1873-76 . "$ Prepared under the direction of the late Sir
C. Wyrille Thomson, and now of John Murray. "Narrative," vol. I., I 885 